\title{
Future of Haemophilia Research in India
}

\author{
Kanjaksha Ghosh ${ }^{1} \cdot$ Rinku Shukla ${ }^{1}$
}

Received: 25 July 2017/Accepted: 30 August 2017/Published online: 4 September 2017

(C) Indian Society of Haematology \& Transfusion Medicine 2017

Haemophilia represents high cost low volume disease [1]. Hence in developing countries in the world where $90 \%$ of haemophilia patients lives puts the government of the day in a conundrum ie the limited resources of that country earmarked for health needs to be distributed amongst management and prevention of various diseases which optimally helps the population of the country. Hence there is a need for developing research protocols suitable for that country in an evidence based manner. Haemophilia research in India is one of the examples of need based research, often driven by patients organizations ie Haemophilia federation of India [2]. In last 30 years large number of research papers in haemophilia has contributed materially to our diagnostics, management and training of manpower in the country [3].

However till recently NIIH, Mumbai, AIIMS, New Delhi, CMC vellore were the three Institutions which spearheaded major areas of research in haemophilia ie Management, Diagnosis, complications, Prenatal diagnosis molecular pathology etc [4] several other institutions in India are also increasingly contributing in this area and we hope this number will continue to increase in future, laying the foundation for robust research work in haemophilia and other bleeding disorders in this country.

One of the major areas in which it is happening is the International Clinical trials of many new products which are already in the market or on the horizon. SIPPET trial is one of the best example of that Indian Collaboration with

Kanjaksha Ghosh

kanjakshaghosh@hotmail.com

1 Surat Raktadan Kendra and Research Centre, Udhna Khatodara Urban Health Centre, Udhna Magdalla Road, Surat 395002, India
International community [5]. Haemophilia Federation of India did establish a haemophilia patient registry which has stimulated ICMR to take up this registry and introduce similar registries in common genetic disorders.

Registries often drives significant amount of research in that disorder [6]. It also has important implications for the health planners for resource redistribution and strengthen in diagnosis and management capabilities in the areas of the country where it is most required. A registry helps to compare well being, give prevalence data of various complications of that disorders from previous years in the same country and helps to compare the data from other registries in the world [7, 8]. It also stimulate well balanced clinical trials which are statistically robust and many such trials allow patient to receive costly therapeutic interventions free of cost.

At present Indian haemophilia (Bleeding disorder) registry has close to 20,000 haemophilia patients all over the country, though we expect the number to swell near $85,000-100,000$ when availability of investigative techniques ie coagulation laboratories are available across 750 districts in the country. This project is under consideration by National Rural health Mission. When that happens number of research work, individual case reports etc in haemophilia will increase many folds.

CMC vellore for the last few years is making grounds [9] for Gene therapy in the disease and that will be one of the big areas of research to observe. Our seminal findings showing deficiency of procoagulant proteins or coinheritance of thrombotic genes substantially reduce the clinical severity of bleeding [10] has now been translated into products [11]. At NIIH Mumbai efforts are being made to use clinical modulation of Protein $\mathrm{C}$ levels to get similar results. Development of Plasma based and recombinant based factor concentrate industry in India in near future 
will be another area of operational research which will benefit large number of haemophilia patients. Our study in mutations in haemophilia already gave some direction to develop factor VIII concentrates with supernormal activity [12]. Recombinant proteins incorporating those mutations by various industrial houses of our own country will be a reality. Osteoporosis, Inhibitor formation, hepatitis management will be other areas of research in this disease and this will have long term effect on our haemophilia patients. India already has a strong prenatal disease diagnostic capability in haemophilia. Different laboratories use a combination of techniques [13,14], this area can be further improved by non invasive mode using maternal blood or using in vitro fertilization techniques, in which our country has immense expertise. Further trials on low dose prophylaxis [15], long acting concentrates which could be produced in this country will be interesting to observe. We should not forget carrier mothers, sisters and daughters and occasional female sufferes of this disease. We are sure quite a few research programme involving these groups will emerge in future from our own institutes.

Pain relief is an important component of disease management, so also correction of behavioral problem in this condition, research in complementary therapy can significantly contribute in this area [16]. Studies at National Institute of Immunology using animal models has shown that bone marrow derived allogeneic stem cell could be used to improve bleeding in haemophiliac mice with regeneration and differentiation of allogeneic stem cells into liver cells, this study also could be taken further to see if it can reach clinical trial stage [17]. Allogenic liver transplantation does cure haemophilia [18], though I am not advocating it yet seeing the vast improvement in the expertise technique and outcome in live donor transplantation in our country, who knows that some research will not take place in this direction. We already have a vast number of Hepatitis C/B positive Haemophilia patients, a proportion of them will eventually develop end stage liver disease when such transplantations will be eminently justified.

\section{References}

1. Ghosh K, Ghosh K (2016) Management of haemophilia in developing countries: challenges and options. Indian J Hematol Blood Transfus 32(3):347-355
2. Ghosh K, Shetty S, Sahu D (2010) Haemophilia care in India: innovations and integrations by various chapters of Haemophilia Federation of India (HFI). Haemophilia 16(1):61-65

3. Ghosh K (2004) Management of haemophilia and its complications in developing countries. Clin Lab Haematol 26(4):243-251

4. Ghosh K, Ghosh K, Shetty S (2012) Hemostasis research in India: past, present, and future. Clin Appl Thromb Hemost 18(2):128-133

5. Peyvandi F, Mannucci PM, Garagiola I, El-Beshlawy A, Elalfy M, Ramanan V et al (2016) A randomized trial of factor VIII and neutralizing antibodies in hemophilia A. $N$ Engl J Med 374:2054-2064

6. Shetty S, Shelar T, Mirgal D, Nawadkar V, Pinto P, Shabhag S et al (2014) Rare coagulation factor deficiencies: a countrywide screening data from India. Haemophilia 20(4):575-581

7. Shetty S, Ghosh K (2012) Cancers in patients with hemophilia: a retrospective study from the Italian Association of Hemophilia Centers: a rebuttal. J Thromb Haemost 10(6):1200-1201

8. Shetty S, Sharma N, Ghosh K (2016) Epidemiology of hepatocellular carcinoma (HCC) in hemophilia. Crit Rev Oncol Hematol 99:129-133

9. Sen D, Balakrishnan B, Gabriel N, Agrawal P, Roshini V, Samuel $\mathrm{R}$ et al (2013) Improved adeno-associated virus (AAV) serotype 1 and 5 vectors for gene therapy. Sci Rep 3:1832

10. Shetty S, Vora S, Kulkarni B, Mota L, Vijapurkar M, Quadros L, Ghosh K (2007) Contribution of natural anticoagulant and fibrinolytic factors in modulating the clinical severity of haemophilia patients. Br J Haematol 138(4):541-544

11. Sehgal A, Barros S, Ivanciu L, Cooley B, Qin J, Racie T et al (2015) An RNAi therapeutic targeting antithrombin to rebalance the coagulation system and promote hemostasis in hemophilia. Nat Med 21(5):492-497

12. Nair PS, Shetty S, Ghosh K (2016) Factor VIII antigen, activity, and mutations in hemophilia A. Clin Appl Thromb Hemost 22(4):381-385

13. Shetty S, Ghosh K, Jijina F (2006) First-trimester prenatal diagnosis in haemophilia A and B families-10 years experience from a centre in India. Prenat Diagn 26(11):1015-1017

14. Ranjan R, Biswas A, Kannan M, Meena A, Deka D, Saxena R (2007) Prenatal diagnosis of haemophilia A by chorionic villus sampling and cordocentesis: all India Institute of Medical Science experience. Vox Sang 92(1):79-84

15. Verma SP, Dutta TK, Mahadevan S, Nalini P, Basu D, Biswal N et al (2016) A randomized study of very low-dose factor VIII prophylaxis in severe haemophilia-a success story from a resource limited country. Haemophilia 22(3):342-348

16. Kundu T, Shaikh A, Kutty A, Nalvade A, Kulkarni S, Kulkarni R, Ghosh K (2012) Homeopathic medicines substantially reduce the need for clotting factor concentrates in haemophilia patients: results of a blinded placebo controlled cross over trial. Homeopathy 101(1):38-43

17. Yadav N, Kanjirakkuzhiyil S, Kumar S, Jain M, Halder A, Saxena R, Mukhopadhyay A (2009) The therapeutic effect of bone marrow-derived liver cells in the phenotypic correction of murine hemophilia A. Blood 114(20):4552-4561

18. Ragni MV, Humar A, Stock PG, Blumberg EA, Eghtesad B, Fung JJ et al (2017) Hemophilia liver transplantation observational study. Liver Transpl 23(6):762-768 